\title{
Vapor Phase Ethanol Carbonylation Over Rh Supported on Zeolite 13X
}

\author{
Sara Yacob ${ }^{a}$, Beata A. Kilos ${ }^{b}$, David G. Barton ${ }^{b}$, Justin M. Notestein $^{a *}$ \\ ${ }^{a}$ Northwestern University, Department of Chemical and Biological Engineering, Evanston, IL 60208 USA \\ ${ }^{b}$ The Dow Chemical Company, Core R\&D, Midland, MI 48674 USA
}

Keywords: Ethanol, Ethyl Iodide, Carbonylation, Zeolite 13X, Rhodium

\begin{abstract}
While methanol carbonylation has been extensively studied, higher alcohol carbonylation has received relatively little attention, even though, for example, ethanol carbonylation could be a useful route for the production of propionates. Here we use $\mathrm{Rh} / \mathrm{Na} 13 \mathrm{X}$ to investigate the vapor phase carbonylation of ethanol with an ethyl iodide co-feed. In the base case, the catalyst is $\sim 40 \%$ selective to propionates, with the remainder forming ethylene and diethyl ether. Deposition of additional alkali can increase selectivities to $\sim 60 \%$. Isotopic labeling of ethyl iodide demonstrates reversible formation of ethyl iodide from ethanol, and that preferential incorporation of ethyl iodide initiates the Rh-catalyzed carbonylation cycle. XPS and in situ X-ray absorption spectroscopy are consistent an active anionic $\mathrm{Rh}^{\mathrm{I}}$ iodide species at a zeolite exchange site. This proposed structure and the attendant catalytic reaction network are directly analogous to those of classic solution-phase Rh catalysts and other supported Rh catalysts. However, important differences are noted in the reaction orders and apparent activation barrier, which suggest that the rate of ethyl iodide formation is overall rate limiting under these conditions and for this catalyst.
\end{abstract}

\section{Introduction}

Carbonylation has widely been used to synthesize oxygenates one carbon larger than the feedstock. Methanol carbonylation is an important commercialized process and is currently the leading route to large scale manufacturing of acetic acid.[1] Prior to the 1960s, methanol carbonylation was performed by BASF using a cobalt iodide catalyst.[2] The severe operating conditions $\left(230^{\circ} \mathrm{C}, 600 \mathrm{~atm}\right)$ limited the 
economic advantages of the process and in 1966, Paulik at American Monsanto commercialized a methanol carbonylation process that used a homogenous Rh catalyst.[3] The soluble Rh catalyst operates at comparatively milder conditions ranging from $150-200{ }^{\circ} \mathrm{C}$ and $30-60 \mathrm{~atm}$. Progress in methanol carbonylation since then has been described extensively.[2-5]

The largest commercialized methanol carbonylation processes to date are all via soluble complexes that require a Group VIII transition metal with an iodide co-catalyst, typically methyl iodide. There has been substantial effort to heterogenize or immobilize the metal and conduct carbonylation in the vapor phase. Prior methanol carbonylation work has shown that Rh supported on a type-X zeolite is an effective heterogeneous catalyst in the presence of a methyl iodide co-feed.[6-11] Beyond the Rh/X system, there have been numerous supports investigated specifically for Rh-catalyzed carbonylation, including various zeolites[12-15], silica[10], alumina[16, 17], heteropolyacids[18], carbon[19, 20], and polymers[21, 22]. Aside from $\mathrm{Rh}$, other precious metals and transition metals have been investigated in methanol carbonylation, including $\operatorname{Ir}[23], \mathrm{Ni}[24-29], \mathrm{W}[15], \mathrm{Co}[30]$, and Mo[15, 31] along with several bimetallic systems[32-34]. Commercial processes have been developed using Co (BASF), Rh (Monsanto), and Ir (BP-Cativa) metals.[35] For all of these various methanol carbonylation solid catalysts, an iodide remains a required co-catalyst. In classical methanol carbonylation mechanisms, the alkyl iodide undergoes oxidative addition to the carbonylation catalyst, and following $\mathrm{CO}$ insertion, an acyl iodide reductively eliminates as a precursor to acetic acid.

There have been far fewer studies on ethanol carbonylation to yield propionates. Propionic acid inhibits the growth of both mold and bacteria, which makes it attractive as a food preservative.[36] Additionally, propionates are widely employed as a platform chemical for many industries, including plastics, pharmaceuticals, fragrances, and pesticides.[37] For example, methyl propionate is a chemical intermediate to methyl methacrylate, and subsequently the thermoplastic poly(methyl methacrylate).[38] 
Similar to methanol carbonylation, ethanol carbonylation to propionates has been demonstrated to occur over Group VIII transition metals with iodide co-catalysts. Low valent Group VIII transition metals are characteristically used for the oxidative addition of organic halides to form organometallic halide complexes.[39] There have been a few ethanol carbonylation studies carried out with soluble catalysts very similar to the ones used commercially for methanol carbonylation.[40-49] It is assumed that the carbonylation mechanisms for ethanol in solution are analogous to the established mechanisms for methanol. Regarding solid catalysts, Nefedov et. al. showed that Rh supported on type-X zeolite is able to perform heterogeneous vapor-phase atmospheric pressure carbonylation of ethanol when co-fed with ethyl iodide.[50] Similarly, Scurrell et. al. carried out studies on the selectivity of supported Rh on zeolite catalysts for carbonylation of alcohols.[6, 51] Following this work more than 30 years ago, no additional studies have been presented in the open literature to understand the Rh speciation under reaction conditions or to support the proposed mechanisms by which heterogeneous ethanol carbonylation occurs. Following our own recent work disclosing a new catalyst for ethanol carbonylation, [52] a detailed revisiting of the benchmark catalyst was deemed necessary.

This work uses $\mathrm{Rh} / \mathrm{Na} 13 \mathrm{X}$ for vapor phase carbonylation of ethanol to yield propionates. Extended $\mathrm{X}$ ray absorption fine structure, in situ X-ray absorption near edge spectroscopy, and X-ray photoelectron spectroscopy address the nature of the active Rh catalyst. Isotopic labeling studies and catalytic tests enable us to determine overall reaction barriers and propose a catalytic cycle for ethanol carbonylation by comparison to other Rh catalysts. Finally, we show the influence of adding additional alkali in improving the behavior of these catalysts.

\section{Experimental Details}

2.1 Catalyst Preparation. $1 \mathrm{wt} \% \mathrm{Rh} / \mathrm{Na} 13 \mathrm{X}$ was synthesized using an ion-exchange method between $\mathrm{Rh}$ trichlorohydrate, $\mathrm{Rh}^{\mathrm{III}} \mathrm{Cl}_{3}\left(\mathrm{H}_{2} \mathrm{O}\right)_{\mathrm{X}}$ and Na13X molecular sieves (both procured from Sigma-Aldrich). The linear formula for $\mathrm{Na} 13 \mathrm{X}$ is $\mathrm{Na}_{86}\left[\left(\mathrm{AlO}_{2}\right)_{86}\left(\mathrm{SiO}_{2}\right)_{106}\right]\left(\mathrm{H}_{2} \mathrm{O}\right)_{\mathrm{X}}$ giving an elemental $\mathrm{Si}$ :Al ratio of 1.23. 
$\mathrm{Rh}^{\mathrm{III}} \mathrm{Cl}_{3}\left(\mathrm{H}_{2} \mathrm{O}\right)_{\mathrm{X}}, 20.5 \mathrm{mg}$, was dissolved in $90 \mathrm{~mL}$ of water and heated to $80{ }^{\circ} \mathrm{C}$ with stirring, then $1 \mathrm{~g}$ of Na13X molecular sieves was added to the solution. The ion-exchange solution was left with stirring overnight at $80{ }^{\circ} \mathrm{C}$. After ion-exchange, the aqueous solution was filtered with Whatman grade 42 filter paper (nominal particle retention in liquid $=2.5 \mu \mathrm{m}$ ) which yielded the solid particles. The solid particles were washed with $200 \mathrm{~mL}$ of purified water (Barnstead Nanopure system, purified to $18 \mathrm{M} \Omega-\mathrm{cm}$ resistivity), collected, and dried in a $150{ }^{\circ} \mathrm{C}$ oven overnight. After drying, the solid particles were calcined at $400{ }^{\circ} \mathrm{C}$ in static air, ramping from ambient at $5{ }^{\circ} \mathrm{C} / \mathrm{min}$ and then holding for 2 hours. Prior work has established that performance of this catalyst is only weakly dependent on the ramp rate and ultimate temperature of the pre-treatment.[52]

Additional alkali was also impregnated onto $\mathrm{Rh} / \mathrm{Na} 13 \mathrm{X}$ using $\mathrm{Na}_{2} \mathrm{CO}_{3}, \mathrm{~K}_{2} \mathrm{CO}_{3}$, and $\mathrm{CsHCO}_{3}$, as received from Sigma-Aldrich. The added alkali:Na ratio during synthesis was 1000:1; final weight loadings of the alkali are given in Table S1. The carbonates or bicarbonates were dissolved in $0.3 \mathrm{~mL}$ of purified water and impregnated into $500 \mathrm{mg} \mathrm{Rh} / \mathrm{Na} 13 \mathrm{X}$ with hand mixing until well incorporated. The resulting mixture was dried in a $150{ }^{\circ} \mathrm{C}$ oven overnight. Once dried, the solid material was calcined at $350{ }^{\circ} \mathrm{C}$ in static air, ramping from ambient at $5{ }^{\circ} \mathrm{C} / \mathrm{min}$ and then holding for 2 hours.

2.2 Catalyst Characterization. Inductively coupled plasma atomic emission spectroscopy (ICP-AES) was used to determine Rh, Na, K, and Cs content on the catalysts. For all ICP-AES analyses, catalyst samples were dissolved in a mixture of hydrofluoric acid, hydrochloric acid, nitric acid, and water. The standard solutions were obtained from Sigma-Aldrich at $1000 \mathrm{ppm}$ concentration. ICP-AES standards were diluted from the 1000 ppm solution to known concentrations for calibration using the same stock solutions that samples were dissolved in.

$\mathrm{N}_{2}$ physisorption was carried out on a Micromeritics 2010 ASAP to determine Langmuir surface area and DFT micropore volume. Prior to analysis, samples were degassed under vacuum and at $140{ }^{\circ} \mathrm{C}$ for at least 5 hours. Langmuir surface areas were determined in the range of 10-100 $\mathrm{kPa}$. 
X-ray photoelectron spectroscopy (XPS) was carried out on a Thermo Scientific ESCALAB 250 Xi. Prior to XPS, all powder samples were held under vacuum overnight. During analysis scans, the beam size was $650 \mu \mathrm{m}$, the pass energy was $200 \mathrm{eV}$, the dwell time was $500 \mathrm{~ms}$, and $15-20$ scans were taken for each sample analyzed. All scans were normalized to the $\mathrm{C} 1 \mathrm{~s}$ peak at $284.9 \mathrm{eV}$.

Ammonia temperature programmed desorption $\left(\mathrm{NH}_{3}-\mathrm{TPD}\right)$ was performed on an Altamira Instruments AMI-200. Samples were first heated to $200{ }^{\circ} \mathrm{C}$ under He flow before being cooled and introduced to a $10 \% \mathrm{NH}_{3}$ stream. After $\mathrm{NH}_{3}$ saturation, the samples were heated to $100{ }^{\circ} \mathrm{C}$ again under He flow. The final TPD step was a $10{ }^{\circ} \mathrm{C} / \min$ ramp to $700{ }^{\circ} \mathrm{C}$ under $\mathrm{He}$ flow. Desorbed $\mathrm{NH}_{3}$ was measured using a thermal conductivity detector (TCD) and quantified by comparison to injections of known volumes of $\mathrm{NH}_{3}$.

Rh K-edge extended X-ray absorption fine structure (EXAFS) analysis and X-ray absorption near edge structure (XANES) spectroscopy were performed at the Advanced Photon Source, Argonne National Laboratory. The DuPont-Northwestern-Dow Collaborative Access Team (DND-CAT) bending magnet D at Sector 5 was used. All spectra were collected using a $\mathrm{Si}(111)$ double crystal monochromator operating in transmission mode. For the Rh K-edge, all EXAFS spectra were scanned in the range of $23000 \mathrm{eV}$ to $24200 \mathrm{eV}$, and XANES spectra were scanned in the rage of $23100 \mathrm{eV}$ to $23450 \mathrm{eV}$. Reference samples $\mathrm{Rh}^{\mathrm{III}}$ trichlorohydrate, $\mathrm{Rh}^{\mathrm{III}}$ oxide, tris(triphenylphosphine) $\mathrm{Rh}^{\mathrm{I}}$ chloride, and $\mathrm{Rh}^{\mathrm{III}}$ iodide - were brushed onto Kapton tape and recorded at room temperature. 2-5 scans of each reference were averaged to optimize signal-to-noise ratio.

The EXAFS spectra were normalized and background subtracted using Athena, a program in the iXAFS suite.[53] The Fourier transform (FT) of the $k^{2}$-weighted EXAFS functions, $\chi(k)$, were fitted in the $r$ space using Artemis, another program in the iXAFS suite. The FT $k$ range and fitted $r$ range were 2-11 $\AA$ and $1-4 \AA$, respectively. The amplitude reduction factor was fixed at 0.8 ; the free parameters were interatomic distance $(r)$, coordination number $(\mathrm{CN})$, Debye-Waller factor $\left(\sigma^{2}\right)$, and overall energy shift 
$\left(\mathrm{E}_{0}\right)$. In the fitting procedure for bulk standards, the coordination number for standards was fixed according to the known values of the ligands around the $\mathrm{Rh}$ atom.

XANES experiments were performed using an in situ reaction cell. Freestanding pellets of undiluted catalyst were supported in the sample holder as gas and vapor feeds passed across the sample. As for the catalytic runs, the fresh material was initially calcined at $400{ }^{\circ} \mathrm{C}$ in static air. No effort was made to protect the sample from ambient conditions during the transfer to the in situ cell. The in situ cell was temperature controlled using heating tape and an external temperature controller. Spectra were acquired starting at room temperature and under inert gas conditions. During reaction, the temperature was $200{ }^{\circ} \mathrm{C}$ while $\mathrm{CO}$, ethanol, and ethyl iodide flowed through the cell, with gas flow rates controlled by a glass rotameter. A XANES spectrum was acquired every 10 min during the 12 hour reaction. XANES spectra were normalized and background subtracted using Athena, and principal component analyses were carried out using GRG nonlinear least squares fitting implemented in MS-Excel.

2.3 Carbonylation Experiments. Gas phase reactions were carried out in 1/4" OD plug flow microreactors constructed of Hastelloy C-276. Packed beds were supported by quartz wool and contained $20 \mathrm{mg}-200$ $\mathrm{mg}$ of $1 \mathrm{wt} \% \mathrm{Rh} / \mathrm{Na} 13 \mathrm{X}$, depending on the desired space velocity, without additional diluent. The catalyst powder was sieved to between 100-120 $\mu \mathrm{m}$. Ethanol and ethyl iodide were delivered by liquid syringe pump and vaporized into the $\mathrm{CO}$ feed upstream of the reactor. Ethanol and ethyl iodide were acquired from Sigma-Aldrich at $\geq 99.5 \%$ purity and used as received without further purification. Ethanol to ethyl iodide ratios varied from 1:1 to 50:1; at standard conditions the ratio was 10:1. CO to ethanol ratios varied from 5:1 to 16:1; at standard conditions the ratio was 15:1. CO was procured from Air Products at $\geq 99 \%$ purity and used after passing through molecular sieve and activated carbon beds to trap moisture and metal carbonyls. Weight hourly space velocities (WHSV) were calculated using gas and vapor mass flow rates and total weight of catalyst. Calculated WHSV ranged from $6-1750 \mathrm{hr}^{-1}$. Reactor temperatures ranged from $160-240{ }^{\circ} \mathrm{C}$ and reactors were maintained at nominal atmospheric pressure. Tabulated data are averages over a minimum of 5 hours time on stream during stable operation. 
Product concentrations were measured using a Shimadzu 2014 Gas Chromatograph - Flame Ionization Detector (GC-FID) with He carrier and a 60 m Restek Stabilwax column programmed with a multi-step temperature ramp from $80-200{ }^{\circ} \mathrm{C}$. Ethylene, diethyl ether (DEE), ethyl iodide (EtI), ethanol (EtOH), ethyl propionate (EP), and propionic acid (PA) were exclusively detected and identified by comparison to retention times of standards. In this document, EP and PA are often referred to collectively as 'propionates'. Signals were correlated to injections of known amounts of these species for calibration. For standard reaction conditions, and unless reported otherwise, these species accounted for all significant features in the chromatogram and together account for a $100 \pm 10 \%$ mol balance on ethyl fragments. Side reactions with $\mathrm{CO}$, such as water gas shift, were not quantified. Conversion, selectivity, and mol balances are all based on ethyl fragments, and are defined as follows, where $n$ is the moles detected in each sample injection:

$$
\begin{aligned}
& \text { Conversion of EtOH }=\frac{n_{E t O H, \text { in }}-n_{E t O H, \text { out }}}{n_{E t O H, \text { in }}} \\
& \text { Selectivity for } E P=\frac{2 n_{E P, \text { out }}}{n_{E \text { thylene,out }}+2 n_{D E E \text { out }}+2 n_{E P, \text { out }}+n_{P A, \text { out }}} \\
& \text { Mol Balance }=\frac{n_{E t O H, \text { out }}+n_{E t I, \text { out }}+n_{E \text { thylene,out }}+2 n_{D E E, \text { out }}+2 n_{E P, \text { out }}+n_{P A, \text { out }}}{n_{E t O H, \text { in }}+n_{E t \text {, in }}}
\end{aligned}
$$

2.4 Isotopic labeling study. During the isotopic labeling study, EtOH carbonylation was carried out with $\mathrm{CH}_{3}{ }^{13} \mathrm{CH}_{2} \mathrm{I}(* \mathrm{EtI})$ co-fed at $210^{\circ} \mathrm{C}, 1$ atm nominal pressure, $44 \mathrm{hr}^{-1} \mathrm{WHSV}$, and a CO:EtOH:*EtI feed ratio of 163:10:1. *EtI was acquired from Sigma-Aldrich and used as received with $>99 \%$ of the EtI containing the isotopic label. After 2 hours time on stream, the products were analyzed using an Agilent 7890A/5975C Gas Chromatograph Mass Selective Detector with an Agilent VF-WAXms column. Ethylene and $\mathrm{CO}$ were unable to be separated in this experiment, and thus the mass balance of labeled ethyl fragments could not be closed. 


\section{Results and Discussion}

3.1 Ethanol Carbonylation. There are four major products (ethylene, DEE, EP, and PA) detected in the vapor phase carbonylation reaction of EtOH with EtI over $\mathrm{Rh} / \mathrm{Na} 13 \mathrm{X}$ catalysts under near-steady state conditions (Figure 1), arranged in two primary reaction pathways: dehydration and carbonylation. $\mathrm{H}_{2} \mathrm{O}$ is necessarily formed from the dehydration products, but not quantified. In the presence of $\mathrm{H}_{2} \mathrm{O}$ and under reaction conditions, water-gas shift can also occur yielding $\mathrm{H}_{2}$ and $\mathrm{CO}_{2}$, but the extent of water gas shift activity was not quantified with this detection scheme. [54, 55] Carbonylation of EtOH does not occur over the Na13X support alone - only dehydration to DEE and ethylene (Table 1). Propionate species are formed when $1 \mathrm{wt} \% \mathrm{Rh}$ is supported on $\mathrm{Na} 13 \mathrm{X}$, and there is no evidence of EtOH carbonylation mechanisms enabled solely by acid zeolite sites under these conditions, such as has been observed for dimethyl ether carbonylation.[56-58] All of the data in the discussion that follows have been reproduced on more than a dozen syntheses of $\mathrm{Rh} / 13 \mathrm{X}$ over the course of several years, with variability no greater than that seen within a given run.

Product distributions at $200{ }^{\circ} \mathrm{C}$ are in good agreement with prior studies of EtOH carbonylation over Rh zeolites.[51] Despite observing total propionate selectivity that is lower than what we have reported over Rh-impregnated heteropolyacid (HPA) catalysts under similar conditions, the $\mathrm{Rh} / \mathrm{Na} 13 \mathrm{X}$ catalyst is substantially more active because of the higher temperature of maximum selectivity, giving higher propionate yield (at WHSV $\approx 22 \mathrm{hr}^{-1} \mathrm{Rh} / \mathrm{Na} 13 \mathrm{X}$ propionate yield $=13.3 \%$ and $\mathrm{Rh} / \mathrm{Cs}_{3} \mathrm{PW}_{12} \mathrm{O}_{40}$ propionate yield $=7.6 \%$ ). [52] Ammonia TPD shows the Rh exchanged Na13X catalyst retains $850 \mu$ mol- $\mathrm{NH}_{3} / \mathrm{g}_{\text {cat }}$ acidity, which is only $\sim 0.05 \mathrm{H}^{+} / \mathrm{Al}$, but it is much higher than reported for the fully Cs-exchanged HPA systems that had total acidity less than $35 \mu \mathrm{mol}-\mathrm{NH}_{3} / \mathrm{g}_{\text {cat }}$. Ammonia TPD and additional characterization are available in Table S1. The higher amount of residual acidity remaining on the Na13X catalyst leads to proportionally more competition from dehydration chemistry occurring in parallel with carbonylation. Later we discuss the effect of additional alkali as a route to reduce competitive dehydration. 
3.2 Effect of Weight Hourly Space Velocity. The WHSV was controlled between 6 and $73 \mathrm{~h}^{-1}$ by changing the catalyst weight and the mass flow rate of reactants while maintaining a feed molar ratio of CO:EtOH:EtI at 150:10:1 (Table 1). Except at the lowest WHSV, EtOH conversion increases nearly linearly with space-time across the packed bed, suggesting external diffusion limitations are minimized; significant internal diffusion limitations are not expected given the catalyst particle sizes used and the rates observed. (Figure S1) At high conversion, low WHSV, the propionate selectivity begins to shift from ester to acid as a result of the higher water partial pressure in the reactor due to parallel EtOH dehydration. For example, molar concentrations in the feed are approximately $0.6 \mathrm{~mol} \%$ EtI, $6.2 \mathrm{~mol} \%$ $\mathrm{EtOH}$, and only trace water. At a WHSV of $6 \mathrm{hr}^{-1}$, where EtOH conversion is $59 \%$, the exit molar composition is approximately $0.4 \mathrm{~mol} \%$ EtI, $2.8 \mathrm{~mol} \% \mathrm{EtOH}$, and $2.4 \mathrm{~mol} \% \mathrm{H}_{2} \mathrm{O}$. Total selectivity to propionates (EP + PA) increases at WHSV $6 \mathrm{hr}^{-1}$ up to $62 \%$.

Reactor performance was recorded during an extended time on stream (TOS) experiment to observe any changes in catalyst behavior at standard conditions, Figure 2A. During the 40 hour experiment, the EtOH conversion remained fairly constant near 35\%, indicating no significant deactivation. Selectivity also remained relatively constant between 1.5 and 40 hours. Even when operating at low WHSV (longer residence times across the packed bed) extreme deactivation is not observed. For example, at WHSV 6 hr ${ }^{1}$ (Figure 2B) the EtOH conversion decreases from $66 \%$ to $58 \%$ as the system slowly reaches steady state over the first 6-10 hours of TOS. However, the remaining TOS of the trial showed relatively little change in conversion or selectivity.

\subsection{Effect of Temperature. Figure 3 shows the performance of a $1 \mathrm{wt} \% \mathrm{Rh} / \mathrm{Na} 13 \mathrm{X}$ catalyst operating} within a temperature envelope of $160{ }^{\circ} \mathrm{C}$ to $240{ }^{\circ} \mathrm{C}$ and at $2-3 \%$ conversion. To control conversion, the WHSV was varied while maintaining atmospheric pressure and standard feed conditions (Table S2). Each temperature point is an average of 5 hours TOS at near-steady state conditions. Under standard conditions, EtI and EtOH are $0.6 \mathrm{~mol} \%$ and $6.2 \mathrm{~mol} \%$ of the inlet composition, respectively. At all temperatures, net consumption of EtI was low ( $<10 \%$ conversion) indicating no significant buildup of 
iodide in the reactor or loss as other iodine-containing species relative to the total ethyl feed rate (EtI + $\mathrm{EtOH})$. At all temperatures above $180^{\circ} \mathrm{C}$, ethylene is the product detected in greatest abundance. Selectivity towards ethylene increases with temperature at the expense of DEE, trending in the same direction as the free energies of reaction that favor ethylene at $200{ }^{\circ} \mathrm{C}$ (ethylene $\Delta \mathrm{G}_{\mathrm{r}}=-14.0 \mathrm{~kJ} / \mathrm{mol}$, DEE $\Delta \mathrm{G}_{\mathrm{r}}=-4.7 \mathrm{~kJ} / \mathrm{mol}$; all values per mol ethanol reacted[59]). Ethylene has been previously observed to be the predominant side product.[50]

The selectivity for EP was highest at $200{ }^{\circ} \mathrm{C}(42 \%)$, while the PA was formed at $2 \%$ selectivity or lower at all temperatures, consistent with the high ratio of $\mathrm{EtOH}$ to water at these low EtOH conversions. This maximum in selectivity has not been previously reported in related catalysts; earlier systems reported monotonic decreases in selectivity to propionates with increasing temperature.[7] Because of this maximum in selectivity, a reactor temperature of $200{ }^{\circ} \mathrm{C}$ was used for the remainder of this study. In spite of the maximum in selectivity, propionate yields increased monotonically with temperature, giving a satisfactorily linear Arrhenius plot for total propionate production (Figure S2). The observed activation energy towards propionates was $138 \mathrm{~kJ} / \mathrm{mol}$. This barrier is substantially higher than the barrier previously reported for vapor-phase ethanol carbonylation of $94 \mathrm{~kJ} / \mathrm{mol}[51]$ and also higher than reported values for the homogenous system.[40, 42] Prior studies do not appear to have been run near differential conversion, nor tested for diffusional limitations, so upward revision of the apparent activation barrier is reasonable. The observed barrier is discussed further below.

\subsection{Effect of $\mathrm{CO}$ and EtI Partial Pressure and the Addition of Water. $\mathrm{CO}$ and EtI partial pressures were} independently varied from standard conditions and rates measured. For all tests in Table 2, the total pressure was nominally $1 \mathrm{~atm}$ and the temperature was fixed at $200{ }^{\circ} \mathrm{C}$. When the $\mathrm{CO}$ partial pressure was decreased below standard conditions, He gas was used as a balance to maintain a constant WHSV of 22 $\mathrm{hr}^{-1}$ for all tests. The final two entries of Table 2 show the effect of water addition to the feed. 
With increasing CO partial pressure from 0.3-0.9 atm, carbonylation vs. dehydration selectivities are stable, while EtOH conversion decreases monotonically. This is in contrast to Rh/HPA,[52] where propionate yields increased monotonically with increased CO partial pressures. The former suggests reversible inhibition by $\mathrm{CO}$ coordinated to the $\mathrm{Rh}$ center, while the latter is consistent with $\mathrm{CO}$ addition occurring at the rate limiting step. In the complete absence of EtI (CO/EtOH feed) the conversion of EtOH was less than $1 \%$, with the only detectable products being ethylene and DEE. This was true at all temperatures and WHSV's tested when EtI was excluded, and is unsurprising given the well-documented need for iodide co-catalysts in this system. Alternatively, when EtOH was removed completely from the feed ( $\mathrm{CO} /$ EtI feed) there also were no carbonylation products detected and only ethylene was found in the reactor effluent. Finally, the increase of water in the system drove propionate selectivity towards PA, however, total propionate selectivity decreased at the highest levels of water addition and the total yields suffered.

The ethylene yield plateaus at moderate EtI partial pressures. The relative influences of EtI and CO on ethylene yields indicates that ethylene formation is not only acid-catalyzed, but also catalyzed by Rh and competes with the carbonylation reaction. In contrast, the yield of propionates is nearly linearly dependent on EtI partial pressures until high EtI partial pressures (see Figure S3). In prior work with Rh/HPA,[52] yields were largely independent of EtI feed ratios, suggesting rapid EtI formation and addition to Rh. Here, the apparent near first order dependence of carbonylation at low EtI partial pressure at first glance is consistent with the classic solution phase Rh-catalyzed carbonylation, where the rate-limiting step is EtI addition to the Rh complex.[40, 42] EtI is formed through the reversible condensation reaction between $\mathrm{EtOH}$ and $\mathrm{HI}$ or other iodides present in the system. Thus, if the overall rate-limiting step is the formation of EtI, one step earlier than for classic soluble phase processes, the net reaction will still be first order with respect to added iodide. Using this rate-limiting step also agrees better with the high overall activation energy of $138 \mathrm{~kJ} / \mathrm{mol}$, which is similar to reported values for ethanol dehydration over acid zeolites.[60] While we cannot rule out a higher barrier for EtI addition due to steric or other constraints by 
the zeolite framework, higher barriers and rate-limiting formation of the alkyl iodide have also been observed in the synthesis of anhydrides under low-water conditions,[61] whereas in typical solution phase carbonylation, or over the highly polarizable HPA,[52] the reaction of EtOH and iodide would be expected to be rapid.

The requirement for EtI is demonstrated by exposing $\mathrm{Rh} / \mathrm{Na} 13 \mathrm{X}$ to $\mathrm{CO}$ and EtI (150:10 molar ratio) at $200{ }^{\circ} \mathrm{C}$ and a WHSV of $22 \mathrm{hr}^{-1}$ for 4 hours, giving $15 \%$ EtI conversion and $100 \%$ selectivity to ethylene (Figure 4). By mol balance, the catalyst bed has been loaded with $230 \mathrm{~mol}$ of $\mathrm{HI} / \mathrm{mol}$ of Rh. The feed was then switched to $\mathrm{CO} / \mathrm{EtOH}$ at the same conditions. Carbonylation products were detected for 3 hours but in decreasing selectivity as iodide is slowly flushed from the reactor. Despite the over-saturation of HI, the catalyst is unable to sustainably retain the halide and turn over the carbonylation cycle with only an $\mathrm{EtOH}$ and $\mathrm{CO}$ feed, demonstrating the requirement for EtI to be present in the feed.

3.5 Isotopic Labeling Study. Isotopically labeled *EtI was used to probe how the ethyl species is inserted into the carbonylation catalytic cycle and the origin of side products. After 2 hours TOS at a WHSV of 44 $\mathrm{hr}^{-1}(\mathrm{CO}: \mathrm{EtOH}: * \mathrm{EtI}=163: 10: 1)$, the reactor products were analyzed using GC-MS. The experiment was duplicated using unlabeled EtI for comparison. The normalized mass fragmentation patterns for EtI, EtOH, DEE, and EP are shown in Figure 5A-D. Under these conditions, the EtOH conversion is $26 \%$ and the net EtI conversion is less than 5\%. Even at near zero net consumption of EtI, the effluent EtI was $81 \%$ ${ }^{12} \mathrm{C}$ and $19 \%{ }^{13} \mathrm{C}$ EtI, indicating significant reaction of unlabeled ethanol with liberated iodide. Likewise, the EtOH carried a $5 \%{ }^{13} \mathrm{C}$ label (m/z 46 against $\left.\mathrm{m} / \mathrm{z} 47\right)$. Given the $10: 1 \mathrm{feed}$ ratio of unlabeled and labeled ethyl fragments, the EtOH and EtI are formed reversibly, but they have not reached equilibrium over the length of the reactor at this space velocity.

EP showed $71 \%{ }^{12} \mathrm{C}$ and $29 \%{ }^{13} \mathrm{C}$ incorporation into the propionate fragment. The greater label incorporation than for the level found in the effluent EtI is consistent with EtI initiating the carbonylation catalytic cycle faster than the timescale required for equilibration with $\mathrm{EtOH}$, leading to preferential 
incorporation of the label. Label incorporation into the ethoxy fragment of EP was 9\%, similar to the total fraction of labeled ethyl fragments present in the exiting EtI and EtOH, calculated to be $\sim 7 \%$. This indicates that ester formation is near equilibrium, reacting equally with EtI or EtOH. DEE also showed $\sim 30 \%$ single incorporation of the label and a negligible $2 \%$ double incorporation, indicating substantial formation through cross-reaction of EtI and EtOH. Like carbonylation, the label is not fully equilibrated.

\subsection{EXAFS and in situ XANES. X-ray absorption spectra of $\mathrm{Rh} / \mathrm{Na} 13 \mathrm{X}$ after initial calcination (before} reaction) were compared to $\mathrm{Rh}^{0}, \mathrm{Rh}^{\mathrm{III}}$ trichlorohydrate, and $\mathrm{Rh}^{\mathrm{III}}$ oxide standards. Principal component analysis revealed that the fresh catalyst was $>99 \% \mathrm{Rh}^{\mathrm{III}}$ in an oxygen coordination environment, indicating that the $\mathrm{Cl}^{-}$ions from the precursor were cleanly removed by the calcination treatment (Figure $\mathrm{S} 4)$. Since there is no $\mathrm{Rh}^{\mathrm{III}}$ trichlorohydrate contribution in the fresh catalyst, consistent with XPS studies showing no remaining $\mathrm{Cl}^{-}$ions on the catalyst after calcination (Figure S5), the $\mathrm{Rh}^{\mathrm{III}}$ trichlorohydrate standard was removed from inclusion in further principal component analyses or EXAFS fitting.

Structural parameters obtained from EXAFS analysis are shown in Table S3. Figure 6 shows the $\mathrm{k}^{2}$ weighted FT of the EXAFS spectra (uncorrected) for standards $\mathrm{Rh}$ foil, $\mathrm{Rh}_{2} \mathrm{O}_{3}$, and $\mathrm{RhI}_{3}$ at the $\mathrm{K}$-edge. Fits capture expected scattering distances and number of neighbors: Rh-O at $2.04 \AA$ and Rh-Rh at $2.72 \AA$ for the $\mathrm{Rh}_{2} \mathrm{O}_{3}$ bulk material,[62] Rh-I at $2.65 \AA$ for $\mathrm{RhI}_{3},[63,64]$ and $2.69 \AA$ for $\mathrm{Rh}-\mathrm{Rh}$ in bulk $\mathrm{Rh}$ foil.[64, 65] The molecular $\mathrm{Rh}(\mathrm{I})$ complex tris(triphenylphosphine) $\mathrm{Rh}{ }^{\mathrm{I}} \mathrm{Cl}$ was also considered (Figure $\mathrm{S} 6$ ), but the $\mathrm{Rh}-\mathrm{Cl}$ and $\mathrm{Rh}-\mathrm{P}$ interactions are not representative of any to be found in the experimental materials. Figure 6 also shows the $\mathrm{k}^{2}$-weighted FT of the EXAFS spectra for the fresh Rh/Na13X catalyst. The first peak is attributed to the Rh-O scattering and has a bond-distance of $2.02 \AA$, within error of that of $\mathrm{Rh}_{2} \mathrm{O}_{3}$. No additional features are seen, giving no evidence that the fresh catalyst contains $\mathrm{Rh}-\mathrm{Rh}$ interactions, consistent with isolated Rh cations in an oxygen coordination environment, likely as a mixture of aquo, hydroxo, and framework oxygens; no attempt was made to fit to higher shells that could further refine this fit. This conclusion differs substantially from an older EXAFS study of supported Rh catalysts prepared by a similar method, where large $\mathrm{Rh}_{2} \mathrm{O}_{3}$ crystallites or Rh nanoparticles were seen after 
calcination, depending on the precursor.[64] Unfortunately, the origin of the improved dispersion in this manuscript is not obvious.

The near edge region of the Rh catalyst was studied during two pretreatment stages and an in situ reaction. To assign pseudo-character to the catalyst during the pretreatment and reaction, a principal component analysis was performed on each XANES spectrum taken every 10 minutes (Figure 7, representative individual fit Figure S7). From these principal component analyses, changes in average oxidation state with time were extracted. Fitting references were the $\mathrm{Rh}(\mathrm{III})$ oxide, $\mathrm{Rh}(\mathrm{III})$ iodide, and $\mathrm{Rh}(0)$ metal. It is understood that the conclusions from this analysis may depend on the standards chosen, and future work may include other molecular $\mathrm{Rh}^{0}$ and $\mathrm{Rh}^{\mathrm{I}}$ standards as references. This study did consider tris(triphenylphosphine) $\mathrm{Rh}(\mathrm{I})$ chloride as a fitting reference, but its K-edge energy of $23227.8 \mathrm{eV}$ was unusually high for its formal oxidation state of +1 and it was not used as a reference in the figures that follow. However, comparably good overall fits were obtained when it was included (Figure S8) and conclusions were unchanged regarding the evolution of the average oxidation state with time or fraction iodide character.

To begin, the fresh catalyst was heated from ambient to reaction temperature, $200{ }^{\circ} \mathrm{C}$, under inert $\mathrm{He}$ gas flow. During this initial heating period, principal component analyses of the XANES region show that the average oxidation state of the $\mathrm{Rh}$ species remained near +3 . Once reaction temperature was reached, the gas flow was switched to $\mathrm{CO}$, then vaporized EtOH and EtI were added to the CO flow at a WHSV of $6 \mathrm{hr}^{-1}$ (time $=0$ hour). At time $=0$ hours, when EtOH and EtI are introduced, the catalyst gains some $\mathrm{Rh}^{\mathrm{III}}$ iodide character; this remains fairly constant at $30 \%$ over the course of the reaction, in agreement with the unchanging partial pressure of the added iodide. $\mathrm{Rh}^{\mathrm{III}}$ oxide character drops over the course of the reaction but never disappears, while the contribution from reduced $\mathrm{Rh}$ increases over the first $6 \mathrm{~h}$, then levels out. All together, the average oxidation state of the catalyst drops from +2.6 to +1.7 over the first $6 \mathrm{~h}$, then stabilizes. This 6-hour induction period is very similar to the induction period in product distributions observed with the catalyst when operating at these relatively low WHSV conditions. (Figure 2B). The 
formation of Rh-I species with time is consistent with the EXAFS analysis of the used catalyst. The $\mathrm{k}^{2}$ weighted FT of the EXAFS spectra for the used Rh/Na13X catalyst, Figure 6, shows significant gains in the second scattering peak, which we assign to Rh-I interactions, giving a Rh-I distance of $2.65 \AA$ and a coordination number of 1.1, in addition to a Rh-O distance of $2.07 \AA$ and a coordination number of 1.1. (Table S3) The interaction at $2.07 \AA$ is again in contrast with older work,[64] where only the larger distance peak was observed, more consistent with Rh metal nanoparticles. Elsewhere, Rh supported on zeolite Y has been observed reversibly form metal-metal bonds when under cycles of reducing and oxidizing conditions.[66] Given these reports, the second scatterer could also be assigned to a Rh-Rh interaction, but the overall fit was worse (Table S3) and TEM of the used catalyst was featureless, giving no evidence of Rh nanoparticles.

To reconcile the observed oxidation state and ligand environment, the total $\mathrm{Rh}$ on the catalyst is hypothesized to be present as a mixture of two Rh species under reaction conditions (Figure 8). Specifically, $\sim 80 \%$ of the $\mathrm{Rh}$ is hypothesized to be an anionic $\mathrm{Rh}^{\mathrm{I}} \mathrm{I}$ and the active species for carbonylation. The second species is an oxidized, anionic $\mathrm{Rh}^{\mathrm{III}} \mathrm{I}_{2}$ representing $\sim 20 \%$ of the $\mathrm{Rh}$ on the catalyst. This latter species would be expected to be catalytically inert and to form more readily in the presence of excess iodide. With these two hypothesized Rh complexes, the average Rh-I and Rh-O coordination numbers are each 1.2, consistent with the used catalyst EXAFS results (Table S3). The average oxidation state of 1.4 is in reasonable agreement with the observed average oxidation state of 1.7 from in situ XANES. The $\mathrm{Rh}^{\mathrm{III}}$ species requires two exchange sites in close proximity to each other within a supercage, compared to the $\mathrm{Rh}^{\mathrm{I}} \mathrm{I}$ species that only requires a single exchange site. The Na13X support contains a Si:Al ratio of 1.23, and proximate exchange sites are common. Zeolite supports with higher $\mathrm{Si}$ Al ratios may lead to a greater fraction of the catalyst present in an active form. The net negative charge on these surface complexes would be balanced by the $\mathrm{Na}^{+}$or other alkali present in these materials. 
3.7 XPS Results. XPS was performed on the fresh and used catalyst after a catalytic test at a WHSV of 6 $\mathrm{hr}^{-1}$. The XPS spectra were fit to Gaussians representing contributions from oxidized (+3) and reduced rhodium. The +1 oxidation state reference material, tris(triphenylphosphine) $\mathrm{Rh}^{\mathrm{I}} \mathrm{Cl}$, could not be used in fitting the experimental XPS spectra because it has a non-zero vapor pressure. Other $\mathrm{Rh}^{\mathrm{I}}$ complexes are typically $<0.4 \mathrm{eV}$ shifted from the $\mathrm{Rh}^{0}$ features [67], they are hard to distinguish from the metal in our experimental samples, and we consider only one set of features for 'reduced' Rh sites in the $0 /+1$

oxidation state. The XPS curves for the fresh and used catalyst are shown in Figure 9. The fresh catalyst only contains contributions from $\mathrm{Rh}^{\mathrm{III}}$ species, presumably $\mathrm{Rh}^{\mathrm{III}}$ in oxygen coordination in agreement with the EXAFS and XANES principal component analysis of the fresh catalyst. The used catalyst contains a very broad $\mathrm{Rh}$ feature that can be fit with contributions from multiple $\mathrm{Rh}$ species. To reduce the number of free parameters, the oxidized and reduced $3 d_{3 / 2}$ components were constrained to represent $60 \%$ of the $3 d_{5 / 2}$ peak in the used catalyst, as was the case in the fresh catalyst. The used catalyst XPS spectra were fit to be approximately $58 \%$ reduced and $42 \%$ oxidized character, or an average oxidation state of $1.3-1.8$ (depending on whether the reduced species is counted as $\mathrm{Rh}^{0}$ or $\mathrm{Rh}^{\mathrm{I}}$ ), not dissimilar to the 1.7 average oxidation state estimated from in situ XANES. The average oxidation state as determined from XPS is also in agreement with the hypothesized mixture of two Rh species on the catalyst in Figure 8 that would give an average oxidation state of 1.4 .

3.8 Hypothesized Mechanism. Reports on soluble Rh catalyzed methanol carbonylation have used FTIR and other techniques to show that the $\mathrm{Rh}$ transforms from a $\mathrm{Rh}^{\mathrm{III}}$ pre-catalyst to its active form, an anionic $\mathrm{Rh}^{\mathrm{I}}$ species, $\left[\mathrm{Rh}(\mathrm{CO})_{2} \mathrm{I}_{2}\right]^{-}$, as in established mechanisms. [68, 69] Here, EXAFS analysis and XPS of the catalyst after reaction conditions were consistent with an active complex that is a (zeolite)Rh ${ }^{\mathrm{I}} \mathrm{I}$. Under reaction conditions, the $\mathrm{Rh}$ species likely also has 2 or more coordinated $\mathrm{CO}$, giving a $\left[(\text { zeolite }) \operatorname{Rh}^{\mathrm{I}}(\mathrm{CO})_{2} \mathrm{I}\right]^{-}$located at an exchange site on the $13 \mathrm{X}$.

The mechanism proposed for EtOH carbonylation (Figure 10) is analogous to that of Rh-catalyzed methanol carbonylation. The $\mathrm{Rh}$ cycle is entered through oxidative addition of EtI to the active $\mathrm{Rh}^{\mathrm{I}}$ 
species, $\mathbf{A}$, which is also the primary species proposed from spectroscopy. This addition yields a $\mathrm{Rh}^{\mathrm{III}}$ ethyl complex, $\mathbf{B}$, from which $\mathrm{CO}$ rapidly inserts to the $\mathrm{Rh}^{\mathrm{III}}$-ethyl bond, forming the (zeolite) $\mathrm{Rh}^{\mathrm{III}}(\mathrm{CO})_{2} \mathrm{I}_{2}$-propionate species, $\mathbf{C}$. After $\mathrm{CO}$ adds, $\mathbf{D}$, propionyl iodide reductively eliminates, regenerating the active $\mathrm{Rh}^{\mathrm{I}}$ form of the catalyst, $\mathbf{A}$. We have proposed here beta hydride elimination of ethylene from $\mathbf{B}$ to form species $\mathbf{F}$ to account for the influence of $\mathrm{Rh}$ and $\mathrm{CO}$ on rates of ethanol dehydration. Species $\mathbf{F}$ is also similar to the minority, inactive species proposed from spectroscopy. Finally, we also propose for formation of species $\mathbf{E}$ in the presence of excess $\mathbf{C O}$, a catalytically inactive $\mathrm{Rh}^{\mathrm{I}}$ complex, to explain the inverse dependence of yields on $\mathrm{CO}$ partial pressure. Given the steady conversion with time on stream (after any observed induction periods) the formation of $\mathbf{E}$ appears to be reversible.

There are a number of acid-catalyzed reactions that occur in parallel. The dehydration of EtOH and the dehalogenation of EtI are both acid-catalyzed routes to ethylene, and both would be essentially irreversible at these conditions. The isotopic labeling study suggests that DEE is formed through the bimolecular cross-reaction of EtI and $\mathrm{EtOH}$. As described earlier, the overall rate-limiting step was assigned to be the formation of EtI, shown in step 1 as the reaction of EtOH and HI, but numerous other salts could play the role of iodide shuttle. Finally, the propionyl iodide ejected from the Rh cycle is converted to EP or PA in step 2, depending on the partial pressure of EtOH or $\mathrm{H}_{2} \mathrm{O}$.

3.8 Alkali Addition. The alkali present on the support is hypothesized to play a role in stabilizing the active anionic Rh species, titrating away acid sites, and in shuttling the iodide ions in the rate limiting step. As such, three materials were synthesized with additional alkali impregnated into the $\mathrm{Rh} / \mathrm{Na} 13 \mathrm{X}$ catalyst. After addition of $\mathrm{Na}_{2} \mathrm{CO}_{3}, \mathrm{~K}_{2} \mathrm{CO}_{3}$, or $\mathrm{CsHCO}_{3}$, only moderate amounts of additional alkali were retained, and the acidity decreased slightly. (Table S1) All overexchanged materials showed substantial decreases in dehydration activity due to the reduction in acidity, with $\mathrm{Na}^{+}>\mathrm{K}^{+}>\mathrm{Cs}^{+}$. Overall, the catalyst selectivity towards total propionates reached as high as $62 \%$ (Table 3 ) with only a slight decrease in $\mathrm{EtOH}$ conversion. $\mathrm{K}^{+}$showed improvements in carbonylation yields, suggesting a direct role in 
increasing the rate of iodide addition. The lackluster performance of $\mathrm{Cs}^{+}$may be associated with the decrease in surface and pore volume relative to the parent $\mathrm{Rh} / \mathrm{Na} 13 \mathrm{X}$ (Figure S10) that accompanied addition of this large cation. 


\section{Conclusions}

EtOH carbonylation to propionates has been demonstrated over $\mathrm{Rh} / \mathrm{Na} 13 \mathrm{X}$ with co-catalytic EtI. $\mathrm{Rh}$ was necessary for carbonylation reactions to proceed; only products from dehydration of EtOH were formed otherwise. Carbonylation selectivity was monitored while varying several operating parameters, including temperature, $\mathrm{CO}$ partial pressure, EtI partial pressure, and water addition. $\mathrm{CO}$ was found to have an inhibitory impact on EtOH conversion, presumably caused by reversible coordination and formation of an inactive Rh complex. Propionate yields increase with EtI partial pressure, but the effect diminishes above the standard 1:10 EtI:EtOH feed ratio. Therefore, the proposed rate-limiting step under base case conditions is EtI synthesis, as also consistent with the high apparent activation energy of 138 $\mathrm{kJ} / \mathrm{mol}$. We note that the barrier, and indeed the rate-limiting step, may be very sensitive to the level of acidity, the amount and nature of the added alkali, and the relative amounts of iodide and water present at reaction conditions. Continuous feeds of EtI are necessary, as has been seen in earlier systems, and isotopic labeling indicates that EtI was incorporated preferentially into the propionates and diethyl ether.

Through XPS, EXAFS, and XANES, the Rh oxidation state and coordination environment were determined. The catalyst appears to transform from an isolated $\mathrm{Rh}^{\mathrm{III}}$ to an average oxidation state of 1.4 under reaction conditions and afterwards. The working catalyst is proposed to be a mixture of an active anionic $\mathrm{Rh}^{\mathrm{I}} \mathrm{I}$ supported at an exchange site on the zeolite $(\sim 80 \%)$ and an inactive $\mathrm{Rh}^{\mathrm{III}}$ species $(\sim 20 \%)$. Overall, the catalyst is proposed to carry out carbonylation by a simple modification of classical mechanisms, where the limiting step in the vapor phase under differential conversion (very low water) is the formation of the alkyl iodide rather than its oxidative addition. In the base case, carbonylation selectivity is maximized at $\sim 40 \%$, but this was increased to $\sim 60 \%$ with aggressive over-exchange with additional alkali. Balancing acidity and activation of the Rh within different zeolite frameworks and levels of alkali exchange present opportunities for future catalyst optimization. 


\section{Acknowledgements}

The Dow Chemical Company supported this work. This XPS work was performed in the Keck-II facility of NUANCE Center at Northwestern University. The NUANCE Center is supported by the International Institute for Nanotechnology, MRSEC (NSF DMR-1121262), the Keck Foundation, the State of Illinois, and Northwestern University. The CleanCat Core facility acknowledges funding from the Department of Energy (DE-FG02-03ER15457) used for the purchase of the Altamira AMI-200. This EXAFS and in situ XANES work was performed at the DuPont-Northwestern-Dow Collaborative Access Team (DND-CAT) located at Sector 5 of the Advanced Photon Source (APS). DND-CAT is supported by Northwestern University, E.I. DuPont de Nemours \& Co., and The Dow Chemical Company. This research used resources of the Advanced Photon Source, a U.S. Department of Energy (DOE) Office of Science User Facility operated for the DOE Office of Science by Argonne National Laboratory under Contract No. DE-AC02-06CH11357. 
Table 1. Performance of $1 \mathrm{wt} \% \mathrm{Rh} / \mathrm{Na} 13 \mathrm{X}$ catalyst at $200{ }^{\circ} \mathrm{C}$.

\begin{tabular}{lllllll}
\hline Catalyst & WHSV & EtOH & $\begin{array}{l}\text { Ethylene } \\
\text { Sel. (\%) }\end{array}$ & DEE & EP & PA \\
& $\left(\mathrm{hr}^{-1}\right)$ & Conv. (\%) & & Sel. (\%) & Sel. (\%) & Sel. (\%) \\
\hline $\mathrm{Na} 13 \mathrm{X}$ & 22 & 23 & 54 & 46 & 0 & 0 \\
\hline $\mathrm{Rh} / \mathrm{Na} 13 \mathrm{X}$ & 6 & 59 & 32 & 6 & 49 & 13 \\
$\mathrm{Rh} / \mathrm{Na} 13 \mathrm{X}$ & 12 & 45 & 31 & 8 & 52 & 9 \\
$\mathrm{Rh} / \mathrm{Na} 13 \mathrm{X}$ & $22 *$ & 31 & 42 & 14 & 42 & 1 \\
$\mathrm{Rh} / \mathrm{Na13X}$ & 73 & 21 & 33 & 21 & 45 & 0
\end{tabular}

\footnotetext{
${ }^{\mathrm{a}} 200{ }^{\circ} \mathrm{C}, \mathrm{CO}: \mathrm{EtOH}: \mathrm{EtI}=150: 10: 1$, Ethyl mol balance is $100 \pm 10 \%$. EtI conversion $<5 \%$ *standard conditions.
} 
Table 2: Effect of changing reactant partial pressures over $1 \mathrm{wt} \% \mathrm{Rh} / \mathrm{Na} 13 \mathrm{X}$.

\begin{tabular}{|c|c|c|c|c|c|c|c|c|}
\hline \multicolumn{4}{|l|}{ Feed Conditions } & \multicolumn{5}{|c|}{ Product Distribution } \\
\hline $\begin{array}{l}\mathrm{CO}: \mathrm{EtOH}: \mathrm{EtI} \mathrm{H}_{2} \mathrm{O} \\
\text { Molar ratio }\end{array}$ & $\begin{array}{l}\mathrm{P}_{\mathrm{CO}} \\
\text { (atm) }\end{array}$ & $\begin{array}{l}\mathrm{P}_{\mathrm{EtOH}} \\
\text { (atm) }\end{array}$ & $\begin{array}{l}\mathrm{P}_{\mathrm{EtI}} \\
(\mathrm{atm})\end{array}$ & $\begin{array}{l}\text { EtOH } \\
\text { Conv. } \\
(\%)\end{array}$ & $\begin{array}{l}\text { Ethylene } \\
\text { Sel. } \\
(\%)\end{array}$ & $\begin{array}{l}\text { DEE } \\
\text { Sel. }(\%)\end{array}$ & $\begin{array}{l}\text { EP } \\
\text { Sel. } \\
(\%)\end{array}$ & $\begin{array}{l}\text { PA } \\
\text { Sel. } \\
(\%)\end{array}$ \\
\hline $150: 10: 1: 0^{*}$ & 0.903 & 0.088 & 0.009 & 31 & 42 & 14 & 42 & 1 \\
\hline $100: 10: 1: 0$ & 0.602 & 0.088 & 0.009 & 36 & 43 & 14 & 41 & 1 \\
\hline $50: 10: 1: 0$ & 0.301 & 0.088 & 0.009 & 45 & 49 & 9 & 37 & 5 \\
\hline $0: 10: 1: 0$ & 0 & 0.088 & 0.009 & $<1$ & 100 & 0 & 0 & 0 \\
\hline $150: 10: 0: 0$ & 0.911 & 0.089 & 0 & $<1$ & 5 & 95 & 0 & 0 \\
\hline 150: $10: 0.2: 0$ & 0.910 & 0.080 & 0.002 & 12 & 34 & 19 & 47 & 0 \\
\hline $150: 10: 1: 0^{*}$ & 0.903 & 0.088 & 0.009 & 31 & 42 & 14 & 42 & 1 \\
\hline $150: 10: 5: 0$ & 0.873 & 0.085 & 0.042 & 62 & 36 & 3 & 34 & 27 \\
\hline $150: 10: 10: 0$ & 0.837 & 0.081 & 0.081 & 66 & 30 & 2 & 40 & 29 \\
\hline $150: 0: 1: 0$ & 0.990 & 0 & 0.010 & $<5^{\mathrm{t}}$ & 100 & 0 & 0 & 0 \\
\hline $150: 10: 1: 20$ & 0.752 & 0.080 & 0.008 & 24 & 48 & 11 & 33 & 9 \\
\hline $150: 10: 1: 55$ & 0.588 & 0.062 & 0.006 & 19 & 81 & 6 & 0 & 4 \\
\hline
\end{tabular}


Table 3: Performance of support and catalysts at $200{ }^{\circ} \mathrm{C} .{ }^{\mathrm{a}}$

\begin{tabular}{|c|c|c|c|c|c|}
\hline Catalyst & $\begin{array}{l}\text { EtOH } \\
\text { Conv. (\%) }\end{array}$ & $\begin{array}{l}\text { Ethylene } \\
\text { Sel. (\%) }\end{array}$ & $\begin{array}{l}\text { DEE } \\
\text { Sel. (\%) }\end{array}$ & $\begin{array}{l}\text { EP } \\
\text { Sel. }(\%)\end{array}$ & $\begin{array}{l}\text { PA } \\
\text { Sel. }(\%)\end{array}$ \\
\hline $\mathrm{Na}_{13 X^{b}}$ & 23 & 54 & 46 & 0 & 0 \\
\hline $\mathrm{Rh} / \mathrm{Na} 13 \mathrm{X}^{\mathrm{b}}$ & 31 & 42 & 14 & 42 & 1 \\
\hline $\mathrm{Rh}-\mathrm{Na}_{2} \mathrm{CO}_{3} / \mathrm{Na} 13 \mathrm{X}$ & 20 & 36 & 4 & 53 & 7 \\
\hline $\mathrm{Rh}-\mathrm{K}_{2} \mathrm{CO}_{3} / \mathrm{Na} 13 \mathrm{X}$ & 27 & 34 & 4 & 52 & 10 \\
\hline $\mathrm{Rh}-\mathrm{CsHCO}_{3} / \mathrm{Na} 13 \mathrm{X}$ & 27 & 42 & 10 & 44 & 4 \\
\hline
\end{tabular}

\footnotetext{
${ }^{\mathrm{a}} 200{ }^{\circ} \mathrm{C}, \mathrm{WHSV}=22 \mathrm{hr}^{-1}, \mathrm{CO}: \mathrm{EtOH}: \mathrm{EtI}=150: 10: 1$. Ethyl mol balance $100 \pm 5 \%$. EtI conversion $<5 \%$.

${ }^{\mathrm{b}}$ repeated from Table 1
} 


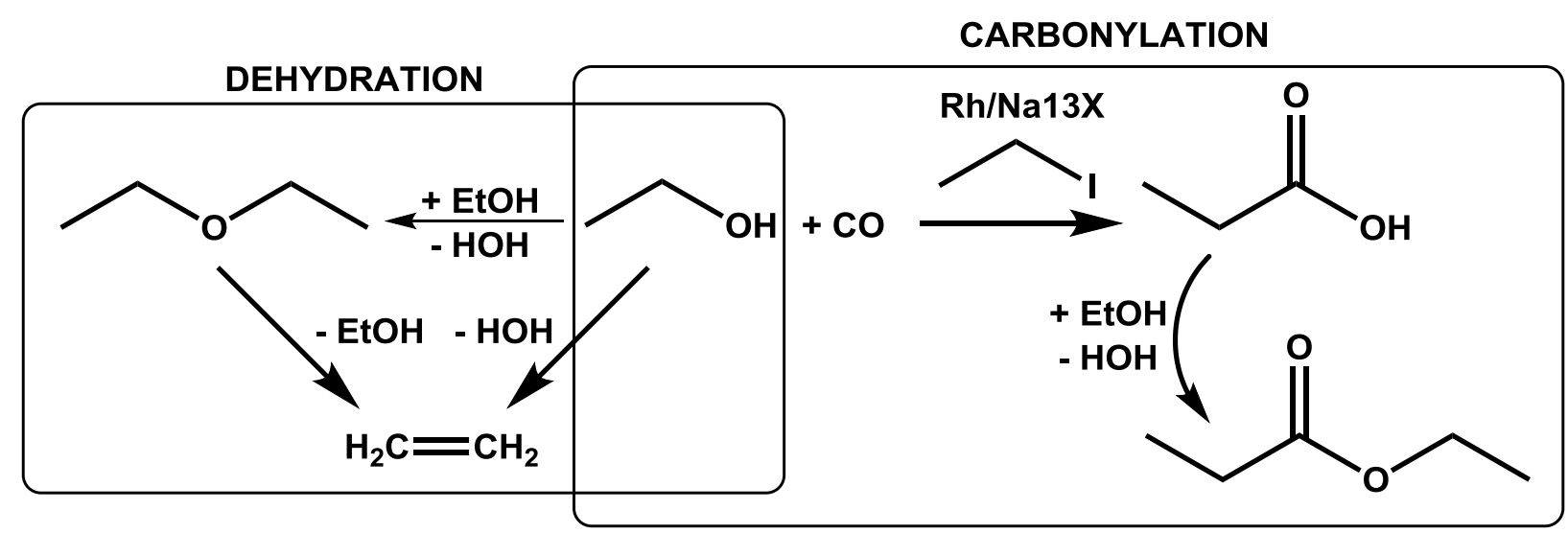

Figure 1. The overall reaction network for $\mathrm{EtOH}$ dehydration and carbonylation. 

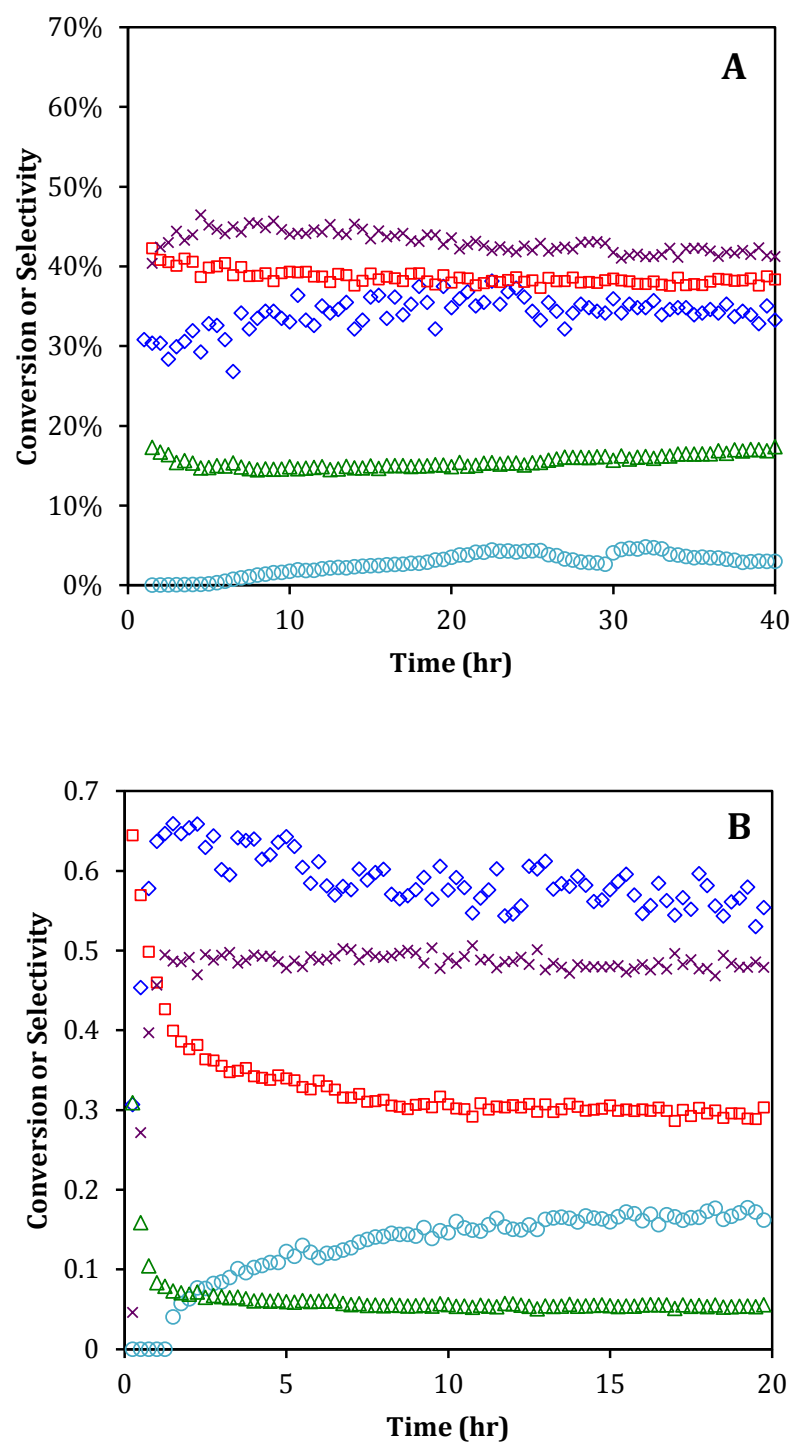

Figure 2. Extended time on stream of $1 \% \mathrm{Rh} / \mathrm{Na} 13 \mathrm{X}$ catalyst. $200{ }^{\circ} \mathrm{C}$ and $\mathrm{CO}: \mathrm{EtOH}: \mathrm{EtI}=150: 10: 1 . \mathrm{GC}$ sampling every $0.25-0.5 \mathrm{~h} . \diamond$ EtOH conversion, aethylene selectivity, $\Delta$ DEE selectivity, $\times$ EP selectivity, ○ PA selectivity. (A) operating at a WHSV of $22 \mathrm{hr}^{-1}$, (B) operating at a WHSV of $6 \mathrm{hr}^{-1}$. 


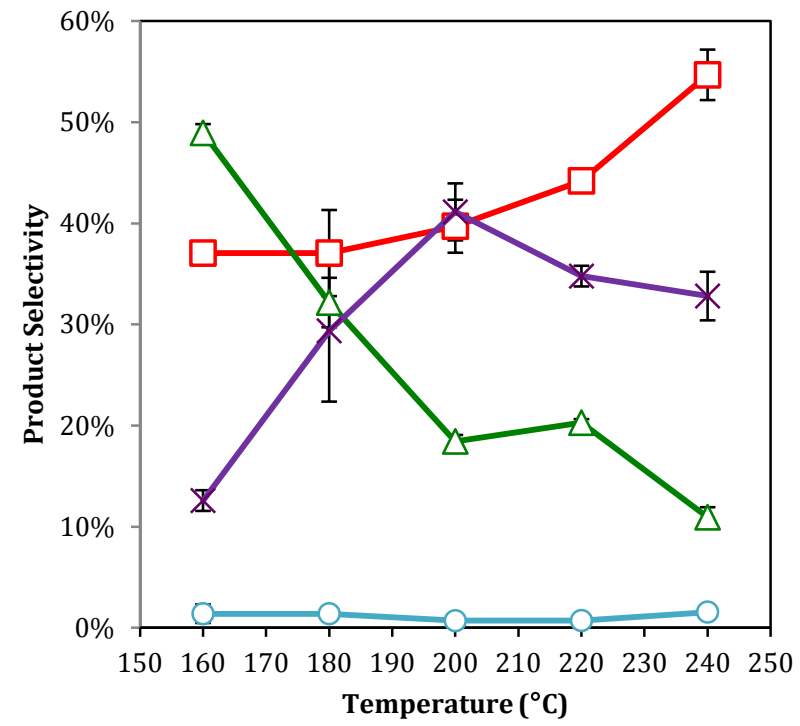

Figure 3. Selectivity of products when using $1 \mathrm{wt} \% \mathrm{Rh} / \mathrm{Na} 13 \mathrm{X}$ catalyst in a $160{ }^{\circ} \mathrm{C}$ to $240{ }^{\circ} \mathrm{C}$ temperature envelope. WHSV $=12-1750 \mathrm{hr}^{-1} . \mathrm{CO}: \mathrm{EtOH}: \mathrm{EtI}=150: 10: 1$. Error bars represent standard deviation during 5 hours TOS. $\square$ ethylene selectivity, $\triangle$ DEE selectivity, $\times$ EP selectivity, $\circ$ PA selectivity. EtOH conversion is $2-3 \%$ for all temperatures. 


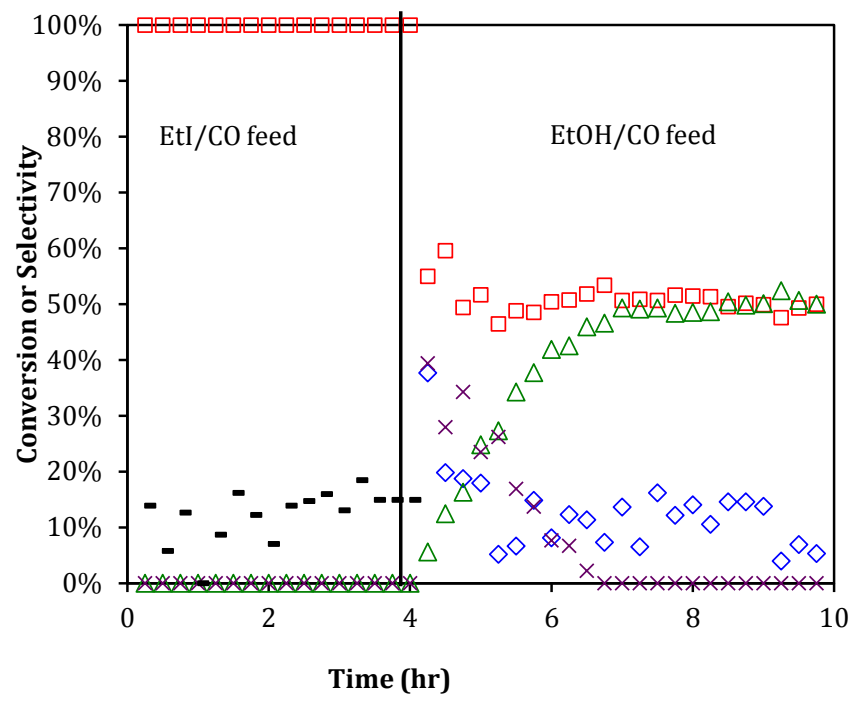

Figure 4. Performance of $1 \mathrm{wt} \% \mathrm{Rh} / \mathrm{Na} 13 \mathrm{X}$ catalyst with feed switched from EtI and $\mathrm{CO}$ to $\mathrm{EtOH}$ and $\mathrm{CO}$ after 4 hours. $200{ }^{\circ} \mathrm{C} . \mathrm{WHSV}=20 \mathrm{hr}^{-1} . \mathrm{CO}: \mathrm{EtI}=15: 1$ or $\mathrm{CO}: \mathrm{EtOH}=15: 1 . \diamond \mathrm{EtOH}$ conversion, $-\mathrm{EtI}$ conversion, $\square$ ethylene selectivity, $\Delta$ DEE selectivity, $\times$ EP selectivity. $\circ$ PA selectivity is $<2 \%$. 
A. EtI

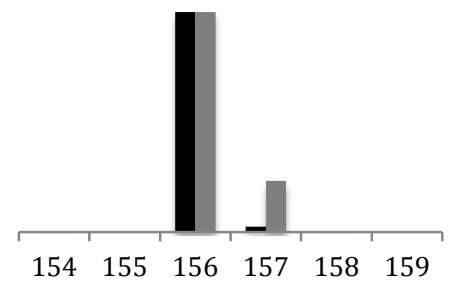

B. EtOH

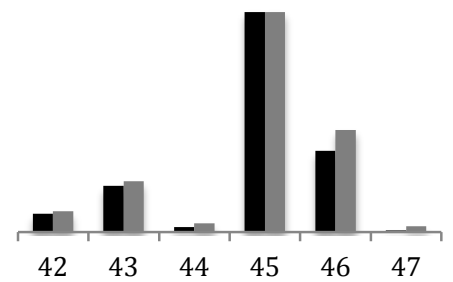

C. DEE

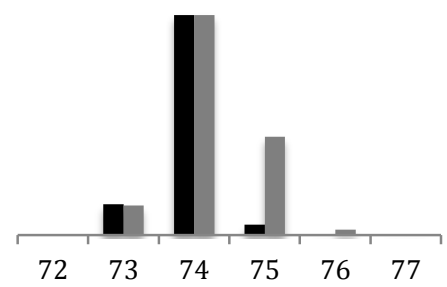

D. EP

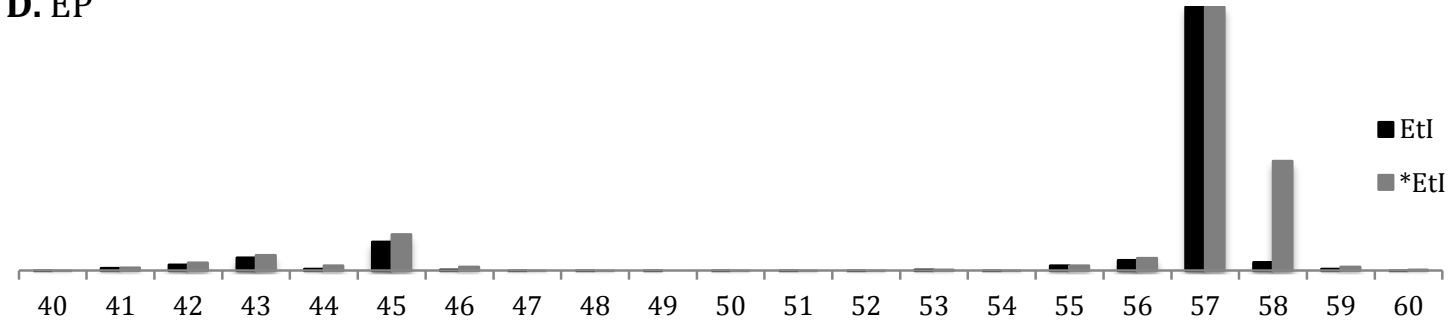

Figure 5. Key fragments of GC-MS spectra, normalized to each of their most intense peaks for (A) EtI,

(B) $\mathrm{EtOH}$, (C) DEE, and (D) EP, detected when operating at WHSV $=44 \mathrm{hr}^{-1}, 210^{\circ} \mathrm{C}$, and CO:EtOH:EtI $=163: 10: 1$ using either labeled *EtI or unlabeled EtI. 


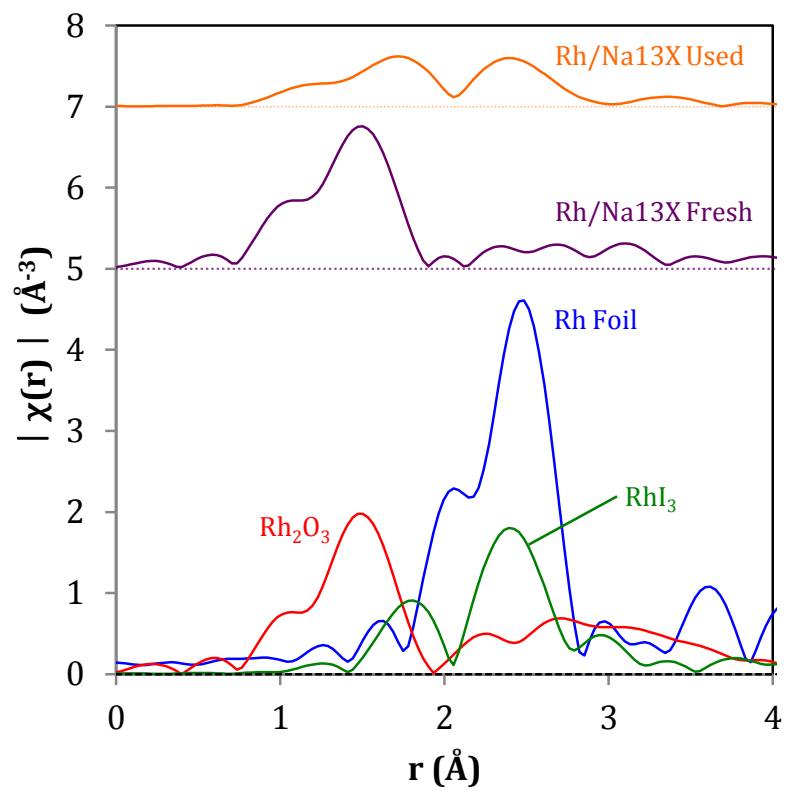

Figure 6. $\mathrm{k}^{2}$-weighted Fourier transformed Rh K-edge EXAFS spectra (fitted in the $\mathrm{r}$ space) of Rh foil, $\mathrm{Rh}_{2} \mathrm{O}_{3}, \mathrm{RhI}_{3}$, and fresh and used $\mathrm{Rh} / \mathrm{Na13X}$ all acquired at $25^{\circ} \mathrm{C}$. 


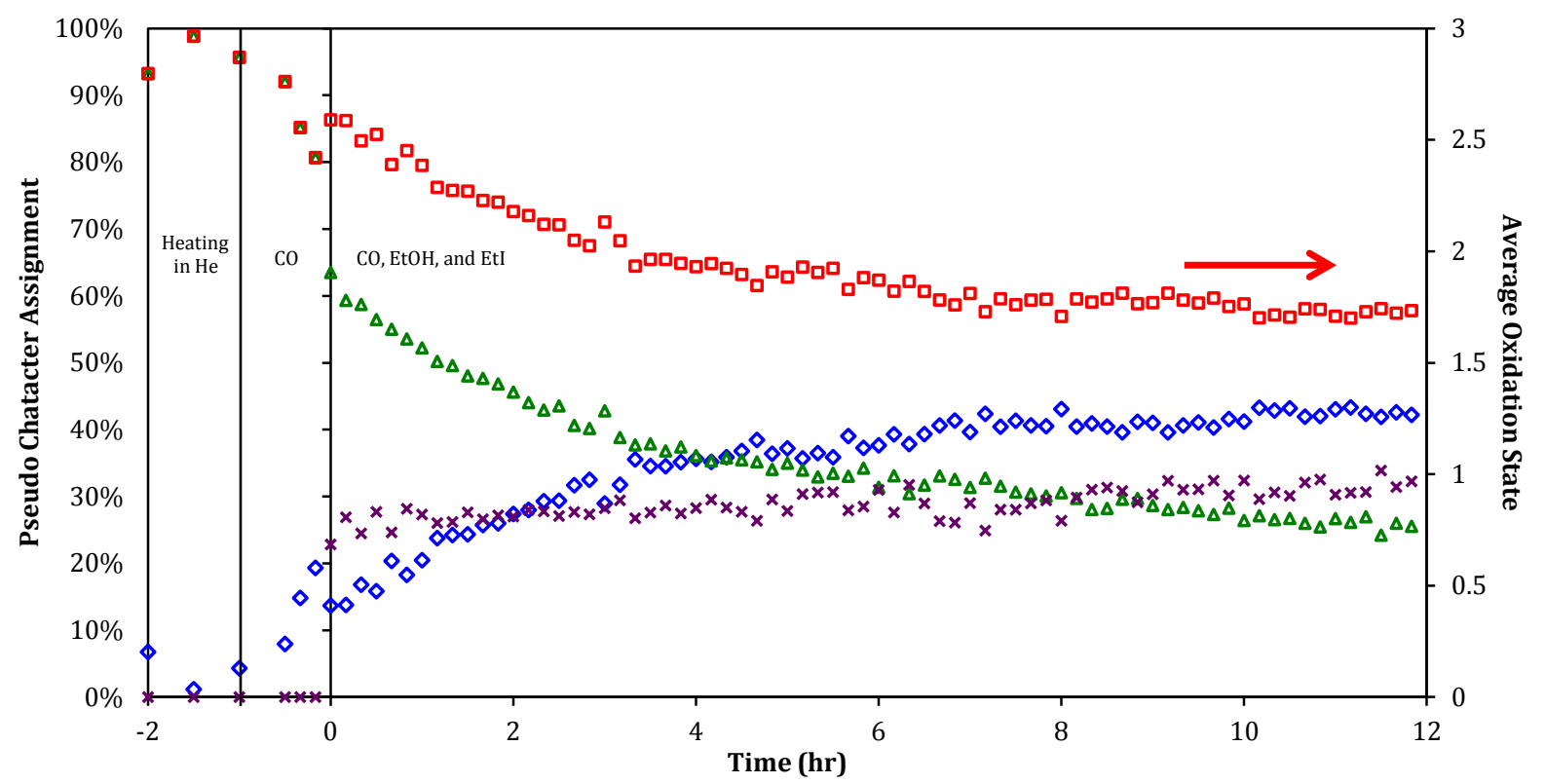

Figure 7. Principal component analyses of in situ XANES and average oxidation state over time for a catalyst under WHSV $=6 \mathrm{hr}^{-1}, 200{ }^{\circ} \mathrm{C}, \mathrm{CO}: \mathrm{EtOH}: \mathrm{EtI}=150: 10: 1 . \diamond \mathrm{Rh}(0), \Delta \mathrm{Rh}(\mathrm{III})$ in an oxygen coordination environment, $\times \mathrm{Rh}(\mathrm{III})$ in an iodide coordination environment, $\square$ average oxidation state (right axis). 

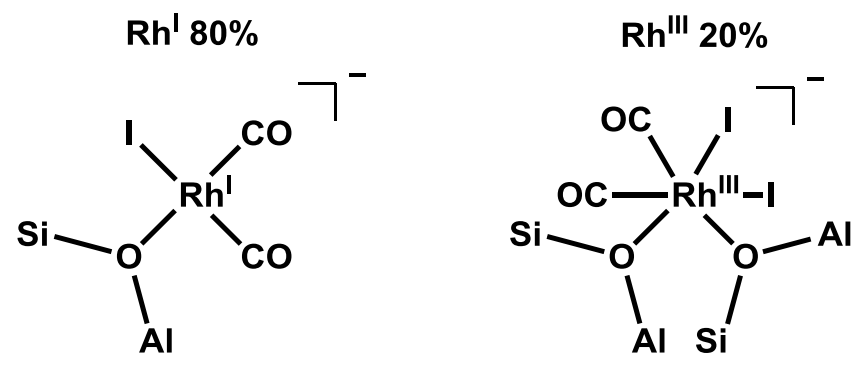

Figure 8. Hypothesized Rh species present during reaction conditions. Not shown are Na counter-cations. 
A

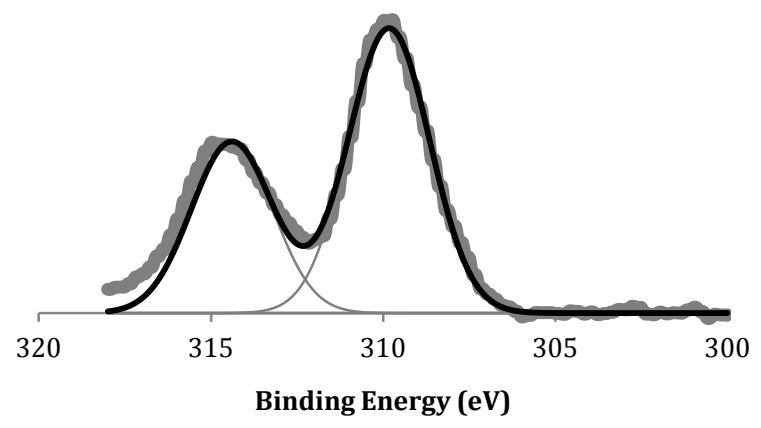

B

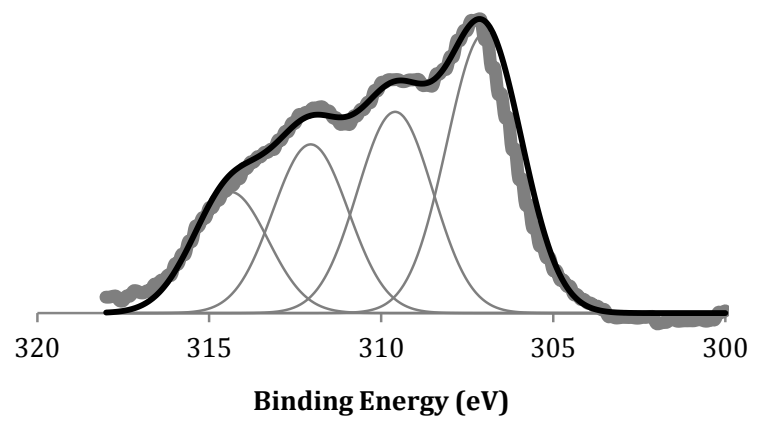

Figure 9. XPS of the fresh and used Rh/Na13X catalyst following reaction at WHSV $=6 \mathrm{hr}^{-1}$. (A) Fresh $\mathrm{Rh} / \mathrm{Na13X}$, (B) Used Rh/Na13X. The XPS spectra were fit to Gaussians representing $3 \mathrm{~d}_{5 / 2}$ and $3 \mathrm{~d}_{3 / 2}$ contributions from oxidized (+3) and reduced (0/+1) Rh species. 


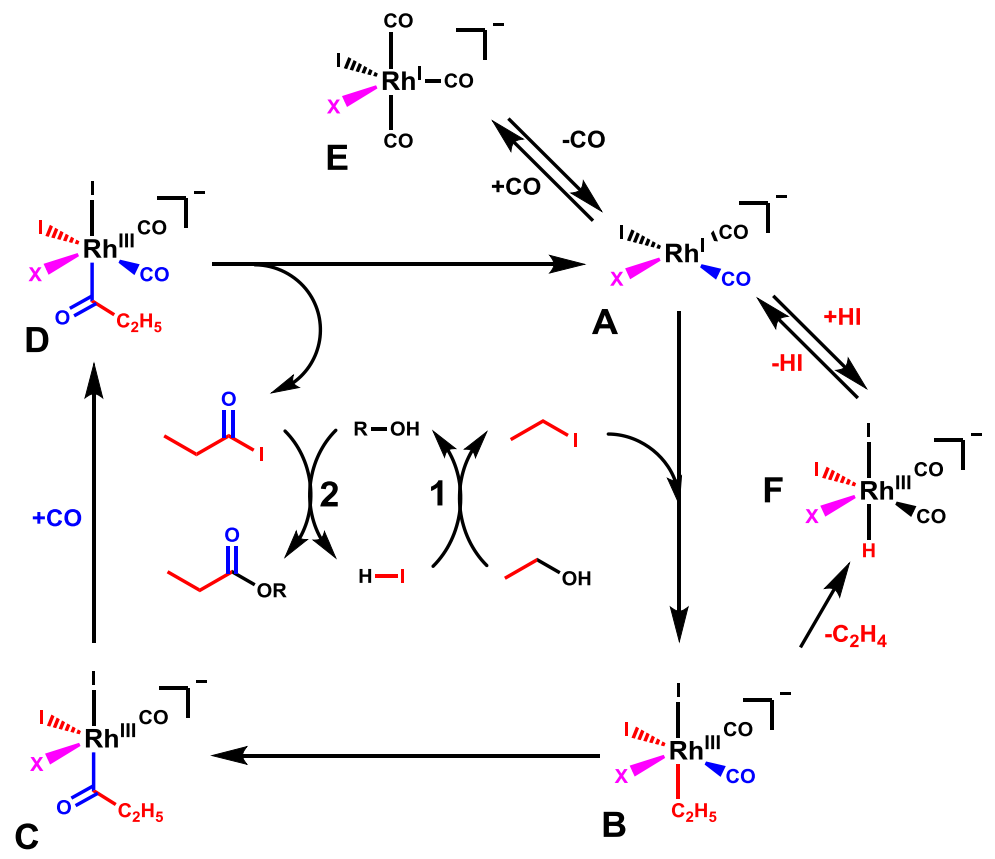

Figure 10. Hypothesized rhodium-catalyzed EtOH carbonylation cycle. Not drawn are the $\mathrm{Na}^{+}$or other alkali counter-cations to the anionic Rh complexes. $\mathbf{X}$ represents a zeolite exchange site. 


\section{References}

[1] G.J. Sunley, D.J. Watson, Catal. Today 58 (2000) 293-307.

[2] P.M. Maitlis, A. Haynes, G.J. Sunley, M.J. Howard, J. Chem. Soc.-Dalton Trans. (1996) 21872196.

[3] F.E. Paulik, J.F. Roth, Chem. Commun. (1968) 1578.

[4] D. Forster, J. Am. Chem. Soc. 98 (1976) 846-848.

[5] J.H. Jones, Platin. Met. Rev. 44 (2000) 94-105.

[6] B. Christensen, M.S. Scurrell, J. Chem. Soc. - Faraday Trans. I 73 (1977) 2036-2039.

[7] B. Christensen, M.S. Scurrell, J. Chem. Soc. - Faraday Trans. I 74 (1978) 2313-2319.

[8] B.K. Nefedov, R.V. Dzhaparidze, Y.T. Eidus, Bull. Acad. Sci. USSR, Div. Chem. Sci. 26 (1977) $1310-1312$.

[9] B.K. Nefedov, R.V. Dzhaparidze, O.G. Mamaev, N.S. Sergeeva, Bull. Acad. Sci. USSR, Div. Chem. Sci. 28 (1979) 348-353.

[10] S.L.T. Andersson, M.S. Scurrell, J. Catal. 71 (1981) 233-243.

[11] S.L.T. Andersson, M.S. Scurrell, J. Catal. 59 (1979) 340-356.

[12] J. Bodis, J. Zsako, C. Nemeth, J. Mink, Vibrational Spectroscopy 9 (1995) 197-202.

[13] M.V. Luzgin, A.G. Stepanov, A. Sassi, J. Sommer, Chem. Eur. J. 6 (2000) 2368-2376.

[14] S. Bischoff, A. Weigt, M. Kant, U. Schulke, B. Lucke, Catal. Today 36 (1997) 273-284.

[15] G.C. Tustin, J.R. Zoeller, H.L. Browning, A.H. Singleton, Carboxylic acids and esters by carbonylation of methanol in a heterogeneous vapour phase, provides improved reaction rates at lower pressure and lower cost, to Eastman Chem Co, (1999) U.S. Patent US5900505-A.

[16] A. Krzywicki, G. Pannetier, Bull. Soc. Chim. France (1975) 1093-1098.

[17] A. Krzywicki, G. Pannetier, Bull. Soc. Chim. France (1977) 64-68.

[18] L.D. Dingwall, A.F. Lee, J.M. Lynam, K. Wilson, L. Olivi, J.M.S. Deeley, S. Gaemers, G.J. Sunley, ACS Catal. 2 (2012) 1368-1376.

[19] F. Li, Q. Qian, F. Yan, G. Yuan, Mater. Chem. Phys. 107 (2008) 310-316.

[20] G. Zehl, S. Bischoff, B. Lucke, Catal. Lett. 19 (1993) 247-255.

[21] N. De Blasio, E. Tempesti, A. Kaddouri, C. Mazzocchia, D.J. Cole-Hamilton, J J. Catal. 176 (1998) 253-259.

[22] E. Tempesti, A. Kaddouri, N. De Blasio, J. Thermal Anal. Calorimetry 53 (1998) 177-187.

[23] C.S. Garland, M.F. Giles, J.G. Sunley, K.E. Clode, S.G. Carl, F.G. Martin, G.S. John, Carbonylation of an alcohol by reaction of methanol with carbon monoxide using a ruthenium or osmium promoted iridium catalyst, to BP Chem. Ltd., (1997) U.S. Patent 5672743. 
[24] S. Bischoff, H.E. Maneck, H. Preiss, K. Fujimoto, Appl. Catal. 75 (1991) 45-56.

[25] S. Yao, C. Yang, Y. Tan, Y. Han, Catal. Commun. 9 (2008) 2107-2111.

[26] N. Zhang, D. Zhou, Y. Zhu, Chin. J. Catal. 27 (2006) 591-595.

[27] K. Fujimoto, T. Shikada, K. Omata, H. Tominaga, Industrial \& Engineering Chemistry Product Research and Development 21 (1982) 429-432.

[28] K. Fujimoto, S. Bischoff, K. Omata, H. Yagita, J. Catal. 133 (1992) 370-382.

[29] T.C. Liu, S.J. Chiu, Ind. Eng. Chem. Prod. Res. Dev. 33 (1994) 488-492.

[30] W.J. Smith, Process for producing carbonylation products, to BP Chem. Ltd. (2009) U.S. Patent 7491842.

[31] T. Shikada, H. Yagita, K. Fujimoto, H. Tominaga, Chem. Lett. (1985) 547-550.

[32] F. Peng, F. Xiao-Bao, Catal. Today 93-95 (2004) 451-455.

[33] H.X. Wang, W.W. Guo, L.J. Zhu, in: T. Sun (Ed.), Energy Eng. and Env. Eng.(2013) 983-986.

[34] T.C. Liu, S.J. Chiu, Appl. Catal. A 117 (1994) 17-27.

[35] A. Haynes, Adv. Catal. 53 (2010) 1-45.

[36] U.S. Environmental Protection Agency, R.E.D. Facts: Propionic Acid, in Pesticides and Toxic Substances, pamphlet 7508W (1991).

[37] Technical Data Sheet: Propionic Acid, The Dow Chemical Company, 2012.

[38] J.J. Spivey, M.R. Gogate, J.R. Zoeller, R.D. Colberg, Ind. Eng. Chem. Res. 36 (1997) 4600-4608.

[39] S. Murai, Activation of Unreactive Bonds and Organic Synthesis, 1999.

[40] J. Hjortkjaer, J.C.A. Jorgensen, J. Mol. Catal. 4 (1978) 199-203.

[41] C. Lai, Q. Chen, Q. Wu, X. Liu, Tianranqi Huagong 33 (2008) 60-64.

[42] S.B. Dake, D.S. Kolhe, R.V. Chaudhari, J. Mol. Catal. 24 (1984).

[43] A.L. Lapidus, E.Z. Gildenberg, A.R. Sharipova, N.F. Kononov, Y.T. Eidus, Kinetics Catal. 17 (1976) 1274-1277.

[44] A.L. Lapidus, O.L. Eliseev, T.N. Bondarenko, N.N. Stepin, Bull. Acad. Sci. USSR, Div. Chem. Sci. 31 (1983) 1852-1858.

[45] R.P. Patil, A.A. Kelkar, R.V. Chaudhari, J. Mol. Catal. 47 (1988).

[46] C. Lai, J. Zeng, Y. Yong, J. Liao, Q. Chen, Tianranqi Huagong 33 (2008) 40-43.

[47] M. Khan, S. Halligudi, S. Shukla, J. Mol. Catal. 48 (1998) L69-L71.

[48] T.W. Dekleva, D. Forster, J. Am. Chem. Soc. 107 (1985) 3565-3567.

[49] G. Jenner, G. Bitsi, J. Mol. Catal. 40 (1987) 71-82. 
[50] B.K. Nefedov, R.V. Dzhaparidze, O.G. Mamaev, Bull. Aca. Sci. USSR., Div. Chem. Sci. 27 (1978) 1448-1450.

[51] M.S. Scurrell, T. Hauberg, Appl. Catal. 2 (1982) 225-238.

[52] S. Yacob, S. Park, B.A. Kilos, D.G. Barton, J.M. Notestein, J. Catal. 325 (2015) 1-8.

[53] B. Ravel, M. Newville, J. Synchrotron Rad. 12 (2005) 537-541.

[54] Y. Lei, N.W. Cant, D.L. Trimm, J. Catal. 239 (2006) 227-236.

[55] E. Trabuco, P.C. Ford, J. Mol. Catal. A 148 (1999) 1-7.

[56] A. Bhan, E. Iglesia, Acc. Chem. Res. 41 (2008) 559-567.

[57] P. Cheung, A. Bhan, G.J. Sunley, E. Iglesia, Angew. Chem. Int. Ed. 45 (2006) 1617-1620.

[58] P. Cheung, A. Bhan, G.J. Sunley, D.J. Law, E. Iglesia, J. Catal. 245 (2007) 110-123.

[59] CRC Handbook of Chemistry and Physics, 95th edition ed., Taylor and Francis Group, LLC, 2014-2015.

[60] H. Xin, X. Li, Y. Fang, X. Yi, W. Hu, Y. Chu, F. Zhang, A. Zheng, H. Zhang, X. Li, J. Catal. 312 (2014) 204-215

[61] J.R. Zoeller, J.D. Cloyd, N.L. Lafferty, V.A. Nicely, S.W. Polichnowski, S.L. Cook, Adv. Chem. (1992) 377-394

[62] R.S. Mulukutla, T. Shido, K. Asakura, T. Kogure, Y. Iwasawa, Appl. Catal. A 228 (2002) 305314.

[63] B.E. Cowie, D.J.H. Emslie, H.A. Jenkins, J.F. Britten, Inorg. Chem. 49 (2010) 4060-4072.

[64] D.R. Denley, R.H. Raymond, S.C. Tang, J. Catal. 87 (1984) 414-423.

[65] A. Gayen, K.R. Priolkar, R. Sarode, V. Jayaram, M.S. Hegde, G.N. Subbanna, S. Emura, Chem. Mater. 16 (2004) 2317-2328.

[66] P. Serna, B.C. Gates, Acc. Chem. Res. 47 (2014) 2612-2620.

[67] J. Kugai, V. Subramani, C.S. Song, M.H. Engelhard, Y.H. Chin, J. Catal. 238 (2006) 430-440.

[68] R. Golhosseini, A. Naderifar, A. Mohammadrezaei, M.J. Nasr, Int. J. Chem. React. Eng. 10 (2012).

[69] N. Yoneda, S. Kusano, M. Yasui, P. Pujado, S. Wilcher, Appl. Catal. A 221 (2001) 253-265. 